\title{
The NSW Health routine screening for domestic violence program
}

\section{Joanne M. Spangaro}

School of Public Health and Community Medicine, University of New South Wales

Email: j.spangaro@student.unsw.edu.au

\begin{abstract}
Routine questioning of women about abuse by their intimate partner has been progressively introduced in NSW in antenatal, early childhood, alcohol and other drug and mental health services since 2001. This was done because of the serious health consequences of domestic violence and the low identification rate of abuse by health services. Following a pilot that found strong support from female patients, this strategy is now well established in NSW public health services. Recent data indicate that approximately 10000 women a month are asked these questions and that $7.3 \%$ of them report experiences of physical abuse or fear caused by their partner or ex-partner within the past 12 months.
\end{abstract}

Domestic violence is the leading contributor to death, disability and illness in women aged $15-44^{1}$ years and results in health costs of $\$ 314$ million annually in Australia. ${ }^{2}$ Routine screening is a low cost measure that is aimed at the identification and early intervention of domestic violence. It has been introduced for women entering antenatal, early childhood, mental health and drug and alcohol services operated by NSW Health. This paper describes the background and key features of this program, current patterns in disclosures and a recently commenced study on the impact of screening.

Research and policy in support of routine screening for domestic violence by health services emerged in the 1990s. This work was led by the USA. The American Medical Association guidelines on partner violence issued in 1992 stated:

'domestic violence and its medical and psychiatric sequelae are sufficiently prevalent to justify routine screening of all women patients in emergency, paediatric, pre natal and mental health settings' ${ }^{3}$
The introduction of screening, which comprises universal, systematic questioning of all female patients in selected services, was seen as an appropriate means to enable health services to identify and respond to patients who are experiencing violence.

The NSW Department of Health drew on this literature when it began to develop a statewide domestic violence policy in 1998. Issues identified were the serious health effects of domestic violence and the high use of health services by victims coupled with low identification of the problem by health services. ${ }^{4}$ Low identification can lead to missed opportunities to refer victims to appropriate services as well as inappropriate health care responses.

\section{The development of the NSW Health initiative}

Following positive staff and stakeholder feedback, the Department piloted screening for domestic abuse by partners in 2000. The pilot took place in one rural and one metropolitan Area Health Service. Review of case files established that screening increased identification of violence. For example, in one of the two Area Health Services where the pilot occurred, a file review of presentations in the participating services revealed that domestic violence was identified in $2 \%$ of cases in a one-month period, compared with $13 \%$ during the pilot period. ${ }^{5}$ In addition, of 586 women who completed post-screening surveys, 97\% supported the program. ${ }^{5}$

In 2001, after further development of tools, all Area Health Services were offered training by the NSW Education Centre Against Violence to implement the screening program. In 2003, the NSW Health document Policy and procedures for identifying and responding to domestic violence, directed all public antenatal, early childhood health, drug and alcohol and mental health services to introduce screening. ${ }^{6}$ The focus on female patients and on partner abuse, as opposed to all forms of family violence, highlights the populations most at risk of serious violence. So too does the selection of these programs, which are those with patient populations among whom prevalence of abuse is either high, the onset of abuse is likely or risk is elevated.

The screening questions are included in the assessment process and built into existing tools such as the Mental Health Outcomes Assessment Tool (MH-OAT). Prior to asking the questions health workers inform patients that all women are asked the same questions, the rationale for 
the questions (violence is widespread and affects women's health), that they may choose not to answer and that confidentiality may be limited if serious risk of harm is disclosed. ${ }^{6}$

The questions asked are:

Q1: Within the last year have you been hit, slapped or hurt in other ways by your partner or ex-partner?

and

Q2: Are you frightened of your partner or ex-partner?

If a woman answers 'yes' to either question, follow up questions are asked to determine whether she wants help and whether she is in immediate danger. Screening only occurs if the woman is alone, and is done on subsequent visits if it can't be performed at first presentation. ${ }^{6}$

\section{Dilemmas in introducing routine questioning}

Asking women about their experiences of violence where this is not the reason for their presentation creates several ethical issues. These include:

- Should women be warned about reporting requirements that will affect the confidentiality of a disclosure?

- Is it fair to ask women these questions if the health system does not have domestic violence services to respond?

- How can workers assist women who are being abused but who may be too fearful to disclose?

- How can women's safety be protected in this process?

Some strategies for addressing these are:

- the preamble which warns women about limited confidentiality,

- the offer of an information card which contains a 24-hour telephone number and key messages, to all women regardless of their response and

- a policy of screening women alone.

The information card is wallet-sized and discrete. It is intended that by giving the card to all women, primary prevention may also occur.

The design and introduction of the initiative was under- taken in close collaboration with service providers. The provision of staff training, scripted questions, an implementation protocol and the use of short and concrete questions are features designed to facilitate and sustain implementation. The literature supports the importance of these factors in implementing screening. The absence of training, ${ }^{7}$ written questionnaires,${ }^{8-10}$ staff time, ${ }^{7}$ policies and institutional support ${ }^{11}$ and monitoring ${ }^{12}$ have all been identified as impediments to maintaining screening for domestic violence.

\section{Monitoring the program}

The NSW Health program is currently monitored by an annual one-month snapshot in which all screening sites copy the screening forms, which are retained in the file, and record the numbers screened. These data are collated and analysed by the Primary Health and Community Partnerships Branch in the Department of Health. The decision not to collect continuous data was made to both minimise staff workload, and to retain an emphasis on the strategy as a clinical rather than a data gathering exercise.

In the month for which the most recent data are available (November 2005), a total of 10090 women were screened. ${ }^{13}$ This is an increase of almost $25 \%$ from the previous year, ${ }^{14}$ and more than double the number screened in 2003.15 If this figure is consistent for all months, then approximately 120000 women presenting to NSW Health Services are asked the questions annually.

Antenatal services are the largest service of those participating in the program, comprising $38 \%$ of the total women screened, followed by early childhood, mental health and alcohol and other drug services. ${ }^{13}$ In addition to the services that were directed by the policy to introduce the questions, several other programs in some Area Health Services have elected to adopt them. These include child health, women's health and sexual health services.

The disclosure rate for domestic violence, defined as a positive answer to either or both of the screening questions, is $7.3 \%$. This figure has remained relatively constant throughout the expansion of the initiative and correlates

Table 1. NSW Health routine screening for domestic violence program - preliminary results for November 2005

\begin{tabular}{|c|c|c|c|c|c|}
\hline & $\begin{array}{l}\text { Number of } \\
\text { eligible women } \\
\text { who presented }\end{array}$ & $\begin{array}{l}\text { Number } \\
\text { screened }\end{array}$ & $\%$ screened & $\begin{array}{c}\text { Number who } \\
\text { answered 'yes' to } \\
\text { Q1 and/or } 2\end{array}$ & $\begin{array}{c}\text { \% who answered } \\
\text { 'yes' to Q1 } \\
\text { and/or } 2\end{array}$ \\
\hline Antenatal & 4679 & 3881 & 83 & 216 & 5.6 \\
\hline AOD & 906 & 754 & 83 & 238 & 31.6 \\
\hline $\mathrm{ECH}$ & 5744 & 3188 & 56 & 73 & 2.3 \\
\hline Mental health & 1577 & 898 & 57 & 119 & 13.3 \\
\hline Women's health & 451 & 361 & 80 & 20 & 5.5 \\
\hline Additional programs & 2933 & 1008 & 34 & 70 & 6.9 \\
\hline Total & 16290 & 10090 & 62 & 736 & 7.3 \\
\hline
\end{tabular}


with the most recent Australian findings that $8 \%$ of women have experienced physical abuse within the past year. ${ }^{16}$ There are, however, significant differences between the different programs, as shown in Table 1.These differences are consistent with the literature describing domestic violence in these populations.

The most common reason for not screening in NSW Health settings in 2005 was the presence of a partner or other person $(60 \%)$. Less than $1 \%$ of women declined to answer the questions. ${ }^{13}$

\section{Current debates in relation to the strategy}

The challenge of maintaining a high screening rate is one of several issues being debated in the literature. Another is whether there is sufficient evidence to justify universal screening. Three systematic reviews question the sufficiency of the evidence to warrant universal screening for domestic violence. ${ }^{17-19}$ Because of these findings, several commentators have proposed that case finding, or asking only where there is a high index of suspicion, is preferred to universal screening. ${ }^{20,21}$ It is not clear, however, how the evidence supports this alternative approach. There is agreement that the term 'screening' is problematic because systematic questioning about violence is not a highly sensitive tool and the problem it identifies, domestic violence, does not have an agreed effective treatment. It is generally considered by proponents of evidence-based medicine that meeting these two tests is necessary before a new screening test is introduced. ${ }^{22,23}$ However, some argue that screening is more than a test, acting as a form of intervention, ${ }^{24,25}$ and enables diagnosis and ongoing clinical care of patients. ${ }^{25,26}$

There also appears to be agreement that further evidence is needed to answer the questions: Does screening reduce abuse? Does it cause harm? What outcomes can be expected?

\section{Impact study}

Under a partnership between the University of New South Wales School of Public Health and Community Medicine and the NSW Department of Health, a mixed methods study is being undertaken that follows up women six months after they are screened. The aim is to determine women's perceptions of the impact of screening on the level of abuse being experienced, actions taken as a result of the screening and changes in attitudes towards abuse and health services. The research will also consider whether the screening has any adverse effects. It is intended that as a result of this study greater understanding of the impact of the NSW Health program will be gained. In addition, it should contribute to the evidence on intervening safely in the health system to interrupt domestic violence.

\section{Acknowledgements}

The input of Gwen Cosier, Primary Health and Community Partnerships Branch, NSW Department of Health who has produced each of the three one-month data snapshot reports is acknowledged. Thanks also go to Professor Anthony Zwi and Dr Ros Poulos, project supervisors, for their input. Funding for the current project is provided by the Australian Research Council and NSW Health.

\section{References}

1. VicHealth. The health costs of violence: measuring the burden of disease caused by intimate partner violence. Department of Human Services, Victoria 2004.

2. Access Economics. The cost of domestic violence to the Australian economy: Part 1. Canberra: Office of the Status of Women, Commonwealth of Australia, 2004.

3. Flitcraft A, Hadley S, Hendricks-Matthews S, McLeer S, Warshaw C. American Medical Association Diagnostic and Treatment Guidelines on Domestic Violence Arch Fam Med 1992; 1: 39-47.

4. NSW Department of Health. Domestic violence: policy discussion paper. Sydney: NSW Health, 1999.

5. Irwin J, Waugh F. Unless they're asked: routine screening for domestic violence in NSW Health - an evaluation report of the pilot project. Sydney: NSW Health, 2001.

6. NSW Department of Health. Policy and procedures for identifying and responding to domestic violence. Sydney: NSW Health, 2003.

7. Waalen J. Screening for intimate partner violence by health care providers: Barriers and interventions. Am J Prev Med 2000; 19(4): 230-7. doi:10.1016/S0749-3797(00)00229-4

8. Stayton C, Duncan M. Mutable influences on intimate partner abuse screening in health care settings: a synthesis of the literature. Trauma Violence Abuse 2005; 6(4): 271-85. doi: $10.1177 / 1524838005277439$

9. Thompson R. Identification and management of domestic violence: a randomized trial. Am J Prev Med 2000; 19(4): 253-63. doi:10.1016/S0749-3797(00)00231-2

10. McLeer S, Anwar AR, Herman S, Maquiling K. Education is not enough: a system failure in protecting battered women. Ann Emerg Med 1989; 18: 651-3. doi:10.1016/S01960644(89)80521-9

11. Campbell J, Coben JH, McLoughlin E, Dearwater S, Nah G, Glass N, Lee D, Durborow N. An evaluation of a systemchange training model to improve emergency department response to battered women. Acad Emerg Med 2001; 8: 131-8.

12. Mezey G, Bacchus L, Haworth A, Bewley S. Midwives perceptions and experiences of routine enquiry for domestic violence Br J Obstet Gynaecol 2003; 110: 744-52.

13. Preliminary data - Primary Health and Community Partnerships Branch, NSW Department of Health, January 2007.

14. NSW Department of Health. Routine screening for domestic violence program: snapshot report 2. Sydney: NSW Health, 2005.

15. NSW Department of Health. Routine screening for domestic violence program: snapshot report 1 . Sydney: NSW Department of Health, 2004. 
16. Mouzos J, Makkai T. Women's experiences of male violence: findings from the Australian component of the International Violence Against Women Survey (IVAWS) in Research and Public Policy Series, No 56. Canberra: Australian Institute of Criminology, 2004.

17. Ramsay J, Richardson J, Carter YH, Davidson LL, Feder G. Should health professionals screen women for domestic violence? systematic review. BMJ 2002; 325: 314-26.

18. Wathen N, Macmillan H, Canadian Taskforce on Preventive Health Care Prevention of violence against women: recommendation statement from the Canadian Task Force on Preventive Health Care. CMAJ 2003; 169(6): 582-4.

19. Nelson H, Nygren P, McInerney Y, Klein J. Screening women and elderly adults for family and intimate partner violence: a review of the evidence for the US Preventive Services Taskforce. Ann Intern Med 2004; 140(5): 387-96.

20. Lachs M. Screening for family violence: what's an evidence based doctor to do? Ann Intern Med 2004; 140(5): 399-400.

21. Hegarty K, Feder G, Ramsay J. Identification of intimate partner abuse in health care settings: should health professionals be screening? Chapter 5. In: Roberts G, Hegarty K,
Feder G, editors. Intimate partner abuse and health professionals: new approaches to domestic violence. London: Elsevier Churchill Livingstone, 2006.

22. Rodriguez MA, Bauer HM, McLoughlin E, Grumbach K. Screening and Intervention for Intimate Partner Abuse: Practices and Attitudes of Primary Care Physicians. JAMA 1999; 282(5): 468-74. doi:10.1001/jama.282.5.468

23. Taket A, Wathen CN, MacMillan H. Should health professionals screen all women for domestic violence? PLoS Med 2004; 1: e4. doi:10.1371/journal.pmed.0010004

24. McFarlane J, Groff JY, O’Brien JA, Watson K. Secondary prevention of intimate partner violence Nurs Res 2006; 55(1): 52-61. doi:10.1097/00006199-200601000-00007

25. Taket A, Nurse J, Smith K, Watson J, Shakespeare J, Lavis V, Cosgrove K, Mulley K, Feder G. Routinely asking women about domestic violence in health settings. BMJ 2003; 327 : 673-6. doi:10.1136/bmj.327.7416.673

26. Janssen P, Hagit D-W, McGregor M. Assessment for Intimate Partner Violence: Where Do We Stand? J Am Board Fam Med 2006; 19: 413-5. 